J. Dairy Sci. 103:1048-1048

https://doi.org/10.3168/jds.2020-103-1-1048

(c) American Dairy Science Association ${ }^{\circledR}, 2020$.

\title{
Corrigendum to "Use of a miniature laboratory fresh cheese model for investigating antimicrobial activities" (J. Dairy Sci. 98:8515-8524)
}

\section{L. Van Tassell, L. A. Ibarra-Sánchez, S. R. Takhar, S. L. Amaya-Llano, and M. J. Miller}

On pages 8516-8517, the second sentence of the paragraph should read (corrected text in in bold) "The milk was combined with $67 \mu \mathrm{L}$ of $\mathbf{0 . 1 5} \mathbf{g} / \mathbf{m L ~} \mathrm{CaCl}_{2}$ and $15 \mu \mathrm{L}$ of commercial rennet diluted to $1 \mathrm{~mL}$ in deionized water."

The authors regret the error.

\section{REFERENCES}

Van Tassell, M. L., L. A. Ibarra-Sánchez, S. R. Takhar, S. L. Amaya-Llano, and M. J. Miller. 2015. Use of a miniature laboratory fresh cheese model for investigating antimicrobial activities. J. Dairy Sci. 98(12):8515-8524. https://doi.org/10.3168/jds.2015-9967. 